\title{
Your Future with Madness: The Relationship between Mental IIIness and Career Goals
}

\author{
Kylie Montgomery ${ }^{1 *}$
}

\begin{abstract} being creative and are more likely to major in humanities.

Keywords

Mental Illness - Career Goals - Introversion - Creativity

${ }^{1}$ Department of World Languages, Literatures \& Cultures, University of North Texas

*Faculty Mentor: Dr. Tom Miles
\end{abstract}

Does someone's mental illness, or lack thereof, affect their career goals? Mental illnesses can affect all parts of someone's daily life. They can directly affect the personality traits of a specific person. But, do they also affect someone's creativity levels? Do they affect someone's future goals? In this study, I examine the exact effect that mental illness has on a person's career goals and if mental illness can be used as an identifier of someone's future path. The results of a unique survey comparing mental health and choice of college majors are presented. They show that students who identify as having anxiety and depression are more likely to identify as

\section{Contents}

\section{Introduction}

1 What Is Creativity?

1

1.1 Madness and Creativity

1.2 Mental Health and Creativity

2 Mental Health and Personality Traits

3 Personality Traits and Career Goals

4 Study Design

5 Results

5.1 Major Groups v. Mental Health

5.2 Major Group v. Creativity

6 Discussion

7 Conclusion

Author Biography

References

\section{Introduction}

Mental illnesses affect many people in modern society. These can be more common mental illnesses such as anxiety and depression or more extreme mental illnesses such as schizophrenia. Mental illnesses can shape many things about a person such as their personality, their actions, and their daily life. When someone has a mental illness, it is truly a defining part of them. This paper investigates whether these mental illnesses have a statistically significant effect on someone's career choice. I will also be giving attention to how creativity plays into all of this. Creativity, for some, is a major factor when choosing a potential career. So, does mental health also affect creativity? This study will determine if a person's mental health can be used to determine a predisposition towards a certain career path and a certain level of creativity.

I will do this by defining correlations between the three. In this paper, I will talk about how mental health and creativity interact according to previously done studies. In my own study, I will be performing my own tests, so I can make an identification of the relationship between the two. I will also talk about how mental health and personality traits influence each other. Personality traits and mental health have a direct, and important, relationship. Personality traits can influence someone's career choice and so the conclusion that mental health does too can be made.

\section{What Is Creativity?} ativity is a multifaceted concept and can be different for everyone.[1, 2, 3] David states that creativity is made up of the process, the person, the product, and the pressure from outside. This emphasizes that creativity is unique to each person and what is creative for one might not be for someone else.[2] So, this almost makes defining creativity even more harrowing of a challenge. How can we define something that is not the same for everyone? We can define what creativity means for one person, but that definition might not fit someone else. Healy, who focused on studying creativity in children, thought an efficient way to detect creativity is to detect patterns of experience in people. He defined creativity as having four characteristics: fluency, flexibility, elaboration, 
and originality. There is a fifth characteristic, that has been set by teachers who work to encourage creativity, and that is evaluation.[3]

Now, what do these characteristics mean when it comes to defining creativity? Fluency is defined as the ability to have various relevant ideas related to the same topic. For example, in five minutes, how many uses can you come up with for some cardboard and duct tape? This can also be seen as resourcefulness. How can you make the most of what you are given? Flexibility is defined as the ability to have different categories or shifts in thinking. This means having the ability to accept new ideas. This also means having ease when shifting between ideas. For example, taking an empty deli meat container and repurposing it as a container for leftovers. Elaboration is having the ability to add details to an idea. For example, let's say you repurposed a mason jar as a small plant holder. Did you just wash and clean it? Or, did you take the time to add a personal touch to it? Repurposing the mason jar is showing your flexibility but when you also decorate it, with ribbons, paint, or any kind of design, you are tapping into that ability to elaborate. Can you take an idea one step further? Originality is a concept that most are familiar with. Can you think of a use for the duct tape and card board that no one else did? Evaluation is defined as the ability to select and refine ideas. This means not jumping on to the first idea that sticks out as unusual and unique. It means taking the time to process and understand the ideas and focusing on the one that is the best option.

While creativity may be different for each person, it follows the same basic concept. Creativity can be focused in one category instead of a general sense of creativity. One person's creativity can be related to things mathematically, for example John Nash, while someone else's creativity is more artistic, and they are able to use new and unique materials to create art. No two people will be creative in the same way, but they will exhibit the five aforementioned characteristics in some capacity.

\subsection{Madness and Creativity}

Dr. Richard Kogan is a doctor with great insight into the psychopathy behind creative genius. He has given a series of lectures on the great musical masters, including Beethoven, Tchaikovsky, Bernstein, and Chopin, and he believes that creative ideas are often produced during periods of chaotic mental state. There is an issue with this because, what defines a chaotic mental state? He also believes that writers and artists have mood disorders in greater proportion than the rest of the general population. Throughout his study he provides a wide range of examples of people with mental illnesses who are considered creative geniuses, such as Vincent van Gogh, Sylvia Plath, and John Nash. They all share the trait of having severe mental illnesses and being considered creative geniuses. He also contends that creativity does not always have to be associated with the liberal arts as in the example of the mathematician John Nash. However, this is anecdotal and not an actual study which means it must be taken with a grain of salt. We also must remember that correlation does not mean causation, but I believe it is an interesting perspective nonetheless.[4]

Dr. Ho also believes in the idea that madness can, in some way, enhance creativity. Dr. Ho is a professor of clinical psychology with a bicultural background between Hong Kong and America. He performed a self-study over his episodes of madness. Over time, he claims to have had 17 episodes of extreme mood elevation. Supposedly, during these states of "madness", he has experienced a depth of feelings, explosions of creativity, and an enhanced ability in memory recall. He documented all the episodes and exercised impulse control. His self-study leads to the conclusion that madness has enriched his life rather than damaged it. This study does provide an example of a mental illness providing heightened creativity from a seemingly reputable source, but there is the issue that this is self-study and it is impossible to eliminate self-bias. Also, how would someone define madness? This state of "madness" is not explicitly defined, so, it seems to be very subjective.[5]

\subsection{Mental Health and Creativity}

In the Viswanath study, a group of high school students of both genders were selected at random to be tested on the correlation between creativity and mental health. The students were given two tests, one that tested creativity and one that tested mental health. The study found that, regardless of gender, those with better mental health exhibited higher creativity.[6] This study does agree with the previous two that mental health affects creativity but not in the same way that they interpreted it to. However, the mental health aspects they were testing were more general as opposed to diagnosable mental health issues. For example, the test did not cover depression or anxiety. These two are issues that I am giving attention to, so it will be interesting to see if there is a difference when the mental health issues are more significant.

On the contrary is Andreasen, who analyzed multiple studies that dive into the realm of our unconsciousness. He gave attention to studies that covered the relationship between mental health and creativity. The consensus amongst these studies that tested creative individuals was that they typically exhibited higher rates of mental illness in comparison to a group of "non-creative" individuals.[7] I believe some of this is relative. I argue that it is impossible for someone to not be creative at all. There are different levels of creativity and some do exhibit it more, but I think it is farfetched to state that someone is "non-creative". A better term would be less creative. I think the results of these studies are significant, but they have issues, nonetheless. When testing the correlation between mental illness and creativity it is more important to test the level of creativity a person possesses. It is not so black and white that you can simply say someone is either creative or not.

However, there is a study that disproves the notion that 
mental illness has any effect on creativity. 33 children ranging from the ages of 7-12 years old were selected from a child and adolescent psychiatric clinic. These 33 children had all been diagnosed with ADHD. Then 33 children with the same gender and age variety, who had not been diagnosed with ADHD, were selected from surrounding schools. The two groups of children were both tested for their creativity levels. The children with ADHD were requested to not take any medication for the study. The children all had to take The Figural TCTT (Tolerance test for creativity thinking) and the Raven Intelligence test. The test measures creativity with four components: fluency, flexibility, originality, and elaboration. The end results showed that there was not a statistically significant difference in the creativity between the children with ADHD and the children without. I believe it could be interesting to see the same test but having the kids with ADHD taking their medicine. Without medicine, some ADHD kids having a much harder time focusing and staying still so with medicine they might be able to perform in ways there were not able to during this study. This could cause another question about the difference in the creativity of treated mental disorders and untreated disorders.[8]

\section{Mental Health and Personality Traits}

Several studies have shown that personality traits, such as social phobia, introversion, and extroversion, can have a direct relationship with a person's mental health. A study that covered the effect that two major personality dimensions, extraversion and neuroticism, have on the genetic and environmental risk for three phobias, social, agoraphobia, and animal phobia, tested a group of roughly 7800 twins of the same sex, both male and female, and opposite genders. Their lifetime phobias and personality traits were tested by a diagnostic interview and a self-report questionnaire. The results showed genetic correlations were moderate and negative between extraversion and social phobia and agoraphobia. Meaning, that the more extraverted a person was, the less at risk for social phobia and agoraphobia they were. There was no correlation between extraversion and animal phobia. For neuroticism, genetic correlations were high and positive with social phobia and agoraphobia. So, contrary to extraversion, the more neurotic a person was, the more at risk for social phobia and agoraphobia they were. Also, because the results were high and positive, this means that for most of the neurotic patients, this was true. For animal phobia the results were moderate. The conclusion made that the genetic variation of extraversion and neuroticism seem to account entirely for the chance of having social phobia and agoraphobia. This study shows that it is not unheard of for mental states to affect other portions of personality. Extraversion and neuroticism had a direct relation with certain phobias. Mental disorders or irregularities can affect many different parts of the brain, meaning, that having a mental disorder that affects the level of someone's creativity is not implausible.[9]

Another study dealing with personality traits and creativ- ity investigated the relation of the Myers-Briggs personality test and social phobia. It also dealt with issues such as depression and anxiety. The goal of the study was to observe the personalities of people with social phobia. 16 patients with social phobia were compared to a normal population of 55,971 and then with 24 hospitalized Major Depressive Disorder patients. The study used the Myers Briggs type indicator to make the comparison. The study showed that patients with social phobia were introverts $93.7 \%$ of the time and the patients from the normal population were introverts $46.2 \%$ of the time.[10] The patients with Major Depressive Disorder also scored very high for introversion. The conclusion made is that social phobia has a significant effect on introversion vs. extroversion.

This study demonstrates that mental illness can have a substantial effect on whether an individual is an extrovert or an introvert. Social phobia has a direct relation to introversion. This, like the extraversion and neuroticism study, highlights that mental illnesses can affect more than just one part of our personalities. This could lead to the conclusion that mental illnesses can have a direct relationship to levels of creativity and/or how "art" orientated a person is.

To continue with the topic of neuroticism and introversion, a study tested whether neuroticism and introversion could be used as indicators for a predisposition to depression. The participants were shown various pictures of emotional facial expressions. The participants who were identified by neuroticism and introversion as having a predisposition to depression, produced results that followed along with the results of depression.[11] This study directly ties personality traits with a mental disorder. It highlights that there is a direct relation between the two. The test was able to pick out people who could have depression based solely on their personality traits.

\section{Personality Traits and Career Goals}

The relation between creativity levels and mental illness ultimately ties back to my original theory that the mental illnesses that effect creativity can also play a role into a person's career choices and goals. A study conducted in China utilized the Cross-Cultural Personality Assessment Inventory-2, or the CPAI-2, to understand the relations between personality traits and the main academic major groups in China. The participants of the study were 989 university students from nine different universities in Hong Kong. The study showed that the results of the CPAI-2 differed greatly between the seven academic groups. This confirmed the ability to use personality traits as predictors of career-relevant choice in China.[12] This study displays that personality traits can directly influence the career choices of people which ties back to the previous studies I mentioned that tie mental illness to personality traits. This can lead to the conclusion that mental illnesses also play a role in someone's career choice.

Humburg's study covers the possibility that the big five personality traits, openness to experience, conscientiousness, 
extraversion, agreeableness, and emotional stability, can be measured at age 14 and used as indicators for study choice in University at age 19 . The study used around 19,391 students who were chosen at random and took a longitudinal Dutch youth survey. Four months after entering secondary education, the students took a part of the Dutch Cito test which is used for getting a better understanding of the secondary education track which may be the best fit for the students. In the second year of the study, the students took the Five-Factor Personality Inventory. The students, who were age 13 at the start of the study, were followed until they finished their education. The data collected over the course of the study was compiled to make correlations.

The study proved that the big five personality traits could be correctly used to predict potential fields of study when in University. For example, students who displayed high levels of extroversion were more likely to choose a field of study in the STEM field. Emotionally stable students have a higher probability of choosing the STEM field as opposed to the Humanities. This study proves that personality traits can be correctly used as indicators of study choice in university. As aforementioned, mental health plays a direct role in personality traits and so the conclusion can be drawn that mental health can play into career choice.[13]

\section{Study Design}

For my study, I created a single survey that contained a compilation of various tests and then distributed it among students at my university. I focused on five major things in the survey. The first section focused on identifying the person's depression levels and the second section for identifying anxiety levels. The third section tested introversion v. extroversion while the forth contained a simple career goals and educational interest questionnaire. The final section covered two different types of creativity tests.

For both the depression inventory and the anxiety index, I made use of Beck's tests. I chose to draw questions from Beck's depression inventory and anxiety index because they were broad and simple to incorporate into a survey format. The depression inventory is made up of 21 multiple choice questions. The questions cover common symptoms of depression, such as loss of motivation, and asks the tester to rank these symptoms. At the end of the test, the points from the questions can be compiled to get a result. The results are as follow: normal ups and downs, mild mood disturbance, borderline depression, moderate depression, and severe depression. The anxiety index works in much the same fashion. There is a chart where on the left-hand side there are 21 symptoms of anxiety listed, then along the top there are the options, not at all, mildly but did not bother me much, moderately it wasn't pleasant at times, and severely - it bothered me a lot. Again, after finishing the test, the points are tallied to determine the diagnosis. The diagnoses for this index are, very low anxiety, moderate anxiety, and cause for concern. I shortened both tests to better fit the survey format and to avoid causing survey burnout. I shortened both tests to ten questions. Through research, I identified the most pertinent questions and put those in. I then calculated a new ranking system that functioned proportionally to those of the originals. For example, on the full anxiety inventory, the highest score someone could get was 63 points while mine the highest was 30 points. On the original, the very low rapking was a score of $0-21$. I then performed a proportion of $\frac{21}{63}=\frac{9}{30}$ to determine the point range. For the introversion v. extroversion section, I made use of a shortened version of the Myers-Briggs inventory. The career goals and educational questionnaire very briefly covered the interests of the test takers. I asked about the person's major and/or minor and their favorite school subjects. I also questioned why they chose the path they did.

Finally, for the creativity portion, I utilized two types of creativity tests. The first is a very simple question that covers the four defined characteristics of creativity, fluency, flexibility, elaboration, and originality. How many different uses can you think of for a paperclip? I encouraged the test takers to be as short or as detailed as they liked. Fluency for this question is measured by how many different ideas they came up with. Flexibility is measured by how many of their ideas were not the typical use for a paperclip. Elaboration covered how detailed their explanations were and then originality is how unique their ideas were. When scoring this question, I had a goal to keep the four aspects as balanced as possible and not let one aspect outweigh the others. This ultimately meant that for scoring purposes, I kept the four aspects separate. For fluency and flexibility, I counted how many ideas they had and how many were not the intended use of a paper clip. Once doing this for every survey response, I found the average and ranked the answer scores as below average, average, and above average. I determined the elaboration score by noting how many of their answers included details and then ranked the scores the same as fluency and flexibility.

Scoring originality was the most challenging. My solution for keeping the score balanced amongst all the answers is as follows. I went through every survey and wrote down their answers starting with the first response. For example, the first response might have been two ideas, the paperclip's intended use and as a lock pick. I then wrote down these two ideas and wrote a number 1 next to them to indicate that survey response 1 answered these. I then did this for all the responses by writing down the new ideas that they had or writing their number down next to a previously stated idea. At the end of all the surveys there were 92 different uses for a paper clip given. Then, using the survey response numbers written next to each idea, I counted how many people listed each idea. At the end of this, there were 13 groups of responses. For example, there were multiple ideas in which 5 people gave them and there were many were only 1 person gave them. These represent 2 of the 13 groups. Then, excluding the "intended use" group since practically everyone gave this answer and it is not original, I assigned a point value to each group. This meant the second most popular idea, a lock pick, 
was given a point value of 1 and that ideas that only had 1 person, received a point value of 12 . Then for each survey response, I calculated their score based on what groupings their ideas were in. Finally, for ranking, I compared responses only to other responses that had the same amount of ideas as them. This is because many people simply gave 3 responses while there was one person who gave 28 . Naturally, the person with 28 responses is going to have a much higher originality score based on the larger opportunity to gain points. I divided the survey responses up into groups based on their amount of ideas and then found the average like that. So, everyone who only gave 3 responses had their score based on others who only gave 3 responses. The average score for this group was 11 points. So, the responses were ranked as below average, average, or above average based upon that.

The second creativity test was a Remote Associates Test (RAT). The goal of a RAT is to measure someone's ability to see relationships between things that are only remotely associated. I used five questions that increased in difficulty. The questions are formatted by given three words that all have a fourth word that is related to them. An example of one of the questions I used contained the three words master/fence/card and the answer to this question is post. Master post, fence post, and post card. I then counted the number of correct answers each person gave, found the average, and again ranked the responses as below average, average, and above average.

\section{Results}

\subsection{Major Groups v. Mental Health}

Results presented in Figure 1. When comparing depression across the three major groups (Humanities, Social Sciences, and STEM), the Humanities had the highest rate and the STEM majors had the lowest. Out of the Humanities majors, $43 \%$ ranked mild mood disturbance, $21 \%$ normal ups and downs, $21 \%$ borderline depression, and $15 \%$ moderate depression. Out of the Social Sciences majors, $42 \%$ ranked normal ups and downs, $26 \%$ mild mood disturbance, $21 \%$ borderline depression, and $11 \%$ moderate depression. Out of the STEM majors, $46 \%$ ranked mild mood disturbance, $32 \%$ normal ups and downs, $18 \%$ borderline depression, and $4 \%$ moderate depression.

For anxiety, (Figure 2) Humanities once again scored the highest and STEM majors the lowest. For Humanities majors, $36 \%$ ranked in the cause for concern category, $36 \%$ for moderate anxiety, and $28 \%$ for very low anxiety. For Social Science majors, $47 \%$ ranked very low anxiety, $37 \%$ cause for concern, and $16 \%$ moderate anxiety. For STEM. $54 \%$ ranked very low anxiety, $43 \%$ moderate anxiety, and $3 \%$ cause for concern. Out of the students who ranked both positive for depression and anxiety, $40 \%$ were Humanities, $40 \%$ were Social Sciences, and $20 \%$ were STEM majors. Out of the students who tested as low in both depression and anxiety, 44\% were STEM majors, $44 \%$ Social Sciences, and $22 \%$ Humanities.

Out of the students who tested average or above average

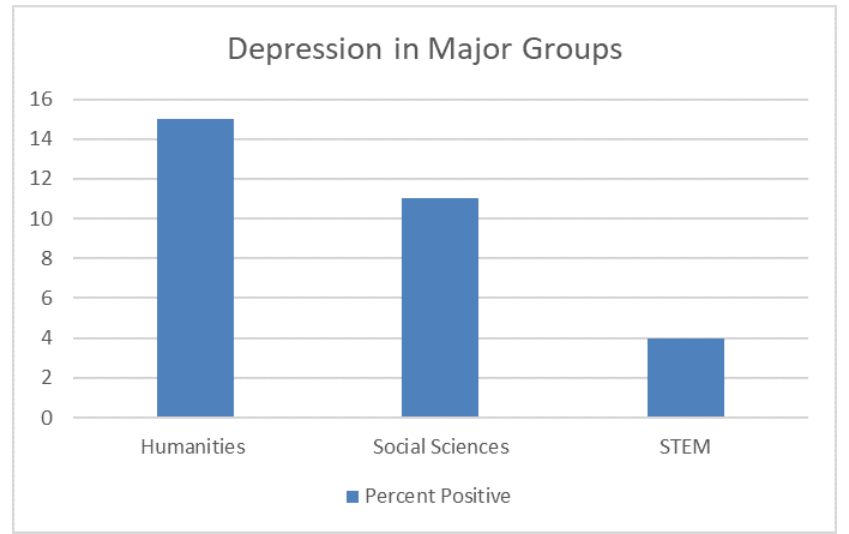

Figure 1. Percent Positive for Depression in Major Groups

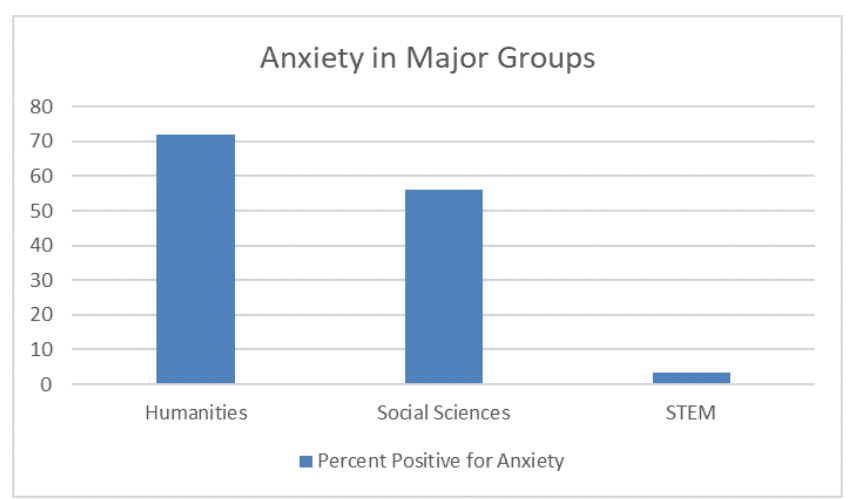

Figure 2. Percent Positive for Anxiety in Major Groups

in fluency and flexibility, $41 \%$ ranked normal ups and downs, $32 \%$ mild mood disturbance, $18 \%$ borderline depression, and $9 \%$ moderate depression. For students who tested average or above average in originality, $43 \%$ ranked mild mood disturbance, $37 \%$ normal ups and downs, $17 \%$ borderline depression, 3\% moderate depression. Finally, out of the students who tested average or above average on the RAT, $36 \%$ ranked mild mood disturbance, $32 \%$ normal ups and downs, $21 \%$ borderline depression, and $11 \%$ moderate depression.

Out of the students who tested average or above average in fluency and flexibility, $41 \%$ ranked moderate anxiety, $36 \%$ very low anxiety, and $23 \%$ cause for concern. For students who test average or above average in originality, $43 \%$ ranked moderate anxiety, $40 \%$ very low anxiety, and $17 \%$ cause for concern. For students ranked average or above average in the RAT, $46 \%$ ranked very low anxiety, $29 \%$ moderate anxiety, and $25 \%$ cause for concern.

\subsection{Major Group v. Creativity}

Results presented in Figure 3. For the Humanities, 31\% tested average or above average in fluency and flexibility, $46 \%$ for originality, and $77 \%$ for the RAT. Out of the Social Sciences, $56 \%$ tested average or above average in fluency and flexibility, $44 \%$ for originality, and $50 \%$ for the RAT. Finally, for STEM majors, $36 \%$ tested average or above average in fluency and flexibility, $60 \%$ for originality, and $36 \%$ for the RAT. 


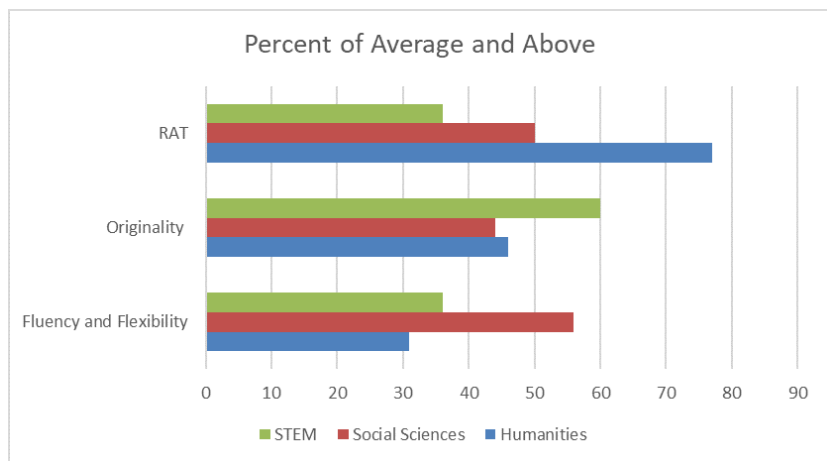

Figure 3. Percent Average and Above for Major Groups

\section{Discussion}

Based on the results, mental health did correlate with both major choice and creativity. For the major groups, Humanities were the highest for both anxiety and depression, while STEM were the lowest. There is a decent difference between the two as well when looking at moderate depression. This is even more obvious with the anxiety test as $36 \%$ of the Humanities were in the cause for concern category and only $3 \%$ of the STEM majors were. Then for creativity, there is a trend of lower depression and/or anxiety equaling higher creativity. The highest-ranking group for creativity switched between the lowest and second lowest diagnoses for both depression and anxiety, and the lowest ranking group was always the most severe of the diagnoses.

As for the major groups v. creativity, there is not a statistically significant trend. Each group ranked the highest in a specific category and ranked the lowest in a specific category. While, this is interesting on its own, there is not a consistent trend. There is also a limitation to this creativity test, and that is human laziness. For some of the answers, it was possible to tell that they just quickly answered the paper clip question and did not give it time. To reach a more significant set of results for this category, I believe a more controlled creativity test must be done. The same can be said for the mental health v. creativity, however, that one did have a more consistent trend.

\section{Conclusion}

So, what do we get from all of this? According to these results, there is a correlation between mental health and major choice, and mental health and creativity. The results for these two comparisons were consistent. Thus, the conclusion that mental health plays a part in someone's career choice and creativity can be made. However, I caution blind acceptance of this. Correlation does not always mean causation. Design limited this study. It was a survey format and given to students who were not monitored when taking it. This means some students who tested low in creativity might have just been lazy that day. It is also important to remember that behind these sets of data are fully faceted people who are shaped by many different things. A third-party presence might have influenced someone's major choice rather than themselves, but they still might have fallen into the trend by coincidence.

In conclusion, according to my results, there is a relationship between mental health, career choice, and creativity. Those who suffer more from depression and anxiety tend to lean towards the Humanities, while those who do not tend to lean towards the STEM field. Furthermore, the better someone's mental health is, the more likely they are to score high in creativity.

\section{Author Biography}

Kylie Montgomery graduated from UNT in 2018. She is currently seeking a position teaching English in Japan.

\section{References}

[1] Genevieve M Cseh, Louise H Phillips, and David G Pearson. Flow, affect and visual creativity. Cognition and Emotion, 29(2):281-291, 2015.

https://doi.org/10.1080/02699931.2014.913553

[2] Laura Teodora David. Testing creativity: a road with many bifurcations. Romanian Journal of Experimental Applied Psychology, 5(2), 2014.

[3] Jane M Healy. Testing for creativity requires a clear definition of what it is. Brown University Child \& Adolescent Behavior Letter, 10(12):1-2, 1994.

[4] N. Timoshin. Creativity and mental illness: Richard Kogan on Rachmaninoff. Psychiatric Times, 33(9):1-3, 2016.

[5] David YF Ho. Madness may enrich your life: A selfstudy of unipolar mood elevation. Psychosis, 8(2):180 $185,2016$.

https://doi.org/10.1080/17522439.2015.1135183

[6] K Viswanath, K Janardhan Reddy, and S Viswanatha Reddy. Effect of mental health on creativity. Indian Journal of Health \& Wellbeing, 6(11), 2015.

[7] Nancy C Andreasen. A journey into chaos: Creativity and the unconscious. Mens sana monographs, 9(1):42, 2011. doi: 10.4103/0973-1229.77424

[8] Banafsheh Aliabadi, Rozita Davari-Ashtiani, Mojgan Khademi, and Fariba Arabgol. Comparison of creativity between children with and without attention deficit hyperactivity disorder: A case-control study. Iranian journal of psychiatry, 11(2):99, 2016.

[9] O Joseph Bienvenu, John M Hettema, Michael C Neale, Carol A Prescott, and Kenneth S Kendler. Low extraversion and high neuroticism as indices of genetic and environmental risk for social phobia, agoraphobia, and animal phobia. American Journal of Psychiatry, 164(11):17141721, 2007.

https://doi.org/10.1176/appi.ajp.2007.06101667

[10] David S Janowsky, Shirley Morter, and Manuel Tancer. Over-representation of myers briggs type indicator introversion in social phobia patients. Depression and Anxiety, 11(3):121-125, 2000. 
${ }^{[11]}$ Gennady G Knyazev, Andrey V Bocharov, Alexander N Savostyanov, and Jaroslav Slobodskoy-Plusnin. Predisposition to depression and implicit emotion processing. Journal of clinical and experimental neuropsychology, 37(7):701-709, 2015.

https://doi.org/10.1080/13803395.2015.1061483

[12] Alexander Ng, Weiqiao Fan, Fanny M Cheung, Frederick TL Leong, and Shu Fai Cheung. The CPAI-2 as a culturally relevant personality measure in differentiating among academic major groups. Journal of Career Assessment, 20(2):196-207, 2012.

https://doi.org/10.1177\%2F1069072711420857

${ }^{[13]}$ Martin Humburg. Personality and field of study choice in university. Education Economics, 25(4):366-378, 2017.

https://doi.org/10.1080/09645292.2017.1282426 